\title{
EDUCANDOS COM DEFICIÊNCIA NO PALCO: METODOLOGIA APLICADA AO DESENVOLVIMENTO DA CRIATIVIDADE E DA AUTONOMIA
}

\author{
EDUCATES WITH DISABILITIES ON THE STAGE: APPLIED METHODOLOGY \\ DEVELOPING CREATIVITY AND AUTONOMY
}
ESTUDIANTES CON DISCAPACIDAD EN ESCENARIO: METODOLOGÍA APLICADA AL DESARROLLO DE LA CREATIVIDAD Y LA AUTONOMÍA

Marcus Vinicius Alves Galvão*

(1) $h$ ttp://orcid.org/oooo-0oo2-6972-6251

Gisele Bizerra da Cunha**

https://orcid.org/oooo-0oo2-6568-2589

Welma Alegna Terra ${ }^{* * *}$

https://orcid.org/oooo-0oo3-4628-5964

\begin{abstract}
REVISTA PEDAGÓGICA
Revista do Programa de Pós-graduação em Educação da Unochapecó | ISSN 1984-1566 Universidade Comunitária da Região de Chapecó | Chapecó-SC, Brasil Como referenciar este artigo: GALVÃO, M. V. A.; CUNHA, G. B.; TERRA, W. A. Educandos com deficiência no palco: metodologia aplicada ao desenvolvimento da criatividade e da autonomia. Revista Pedagógica, Chapecó, v. 22, p. 1-20, 2020.

DOI: https://doi.org/10.22196/rp.v22io.5473
\end{abstract}

RESUMO: O objetivo do presente texto é discutir o musical como ferramenta para a potencialização das diversas habilidades de educandos com deficiência. Com esse intuito, vale destacar a metodologia criada para a realização de um musical, por se tratar de um estudo qualitativo, do tipo descritivo, mas que se constitui no estudo das diversas linguagens artísticas. Assim, a metodologia utilizada na preparação dos educandos para a apresentação foram: montagem das coreografias, preparação psicológica e pedagógica dos educandos, além de ensaios semanais. Como resultado, ressalta-se que o processo de educação e inclusão dos educandos com deficiência pode ser trabalhado de forma significativa, por meio de contribuições advindas da música e da dança, com sua expressão corporal e criativa, independente da padronização ditada pelos meios de comunicação e da indústria da cultura que uniformiza os gostos por determinados produtos, inclusive artísticos que se estabelecem na sociedade do consumo. Conclui-se assim, que as práticas inclusivas com base nas linguagens artísticas possibilitam integrar as diversas dimensões dos sujeitos partícipes desse processo educacional, considerando a perspectiva do seu desenvolvimento físico e emocional e da valorização das suas múltiplas inteligências.

Palavras- chave: Teatro Musical; Educação Especial; Inclusão, Metodologia de vivência; Dança.

RESUMEN: El objetivo del presente texto es discutir lo musical como herramienta para potenciar las diversas habilidades de los estudiantes con discapacidad. Para ello, cabe destacar la metodología creada para la realización de un musical, por tratarse de un estudio cualitativo, de tipo descriptivo, pero que constituye el estudio de los distintos lenguajes artísticos. Así, la metodología utilizada en la preparación de los estudiantes para la presentación fue: montaje de las coreografías, preparación psicológica y pedagógica de los estudiantes, además de ensayos semanales. Como resultado, se enfatiza que el proceso de educación e inclusión de estudiantes con discapacidad se puede trabajar de manera significativa, a través de aportes de la música y la danza, con su cuerpo y expresión creativa, independientemente de la estandarización que dicten los medios. y la industria cultural que unifica los gustos por determinados productos, incluidos los artísticos que se instalan en la sociedad de consumo. Se concluye, por tanto, que las prácticas inclusivas basadas en lenguajes artísticos permiten integrar las diferentes dimensiones de los sujetos que participan en este proceso educativo, considerando la perspectiva de su desarrollo físico y emocional y la valorización de sus múltiples inteligencias.

Palabras clave: Teatro Musical; Educación especial; Inclusión, metodología de la experiencia; Danza.

ABSTRACT: The purpose of this text is to discuss the musical as a tool to enhance the diverse abilities of students with disabilities. To this end, it is worth highlighting the methodology created for the realization of a musical, as it is a qualitative study, of the descriptive type, but which constitutes the study of the various artistic languages. Thus, the methodology used in preparing the students for the presentation were: assembly of the choreographies, psychological and pedagogical preparation of the students, in addition to weekly rehearsals. As a result, it is emphasized that the process of education and 
inclusion of students with disabilities can be worked in a significant way, through contributions from music and dance, with their body and creative expression, regardless of the standardization dictated by the media. and the culture industry that unifies the tastes for certain products, including artistic ones that are established in the consumer society. It is concluded, therefore, that inclusive practices based on artistic languages make it possible to integrate the different dimensions of the subjects participating in this educational process, considering the perspective of their physical and emotional development and the valorization of their multiple intelligences.

Keywords: Musical Theater. Special Education. Inclusion. Experience methodology. Music e Dance.

\section{Introdução}

A resposta que obtive a partir destas inúmeras viagens foi que não há um elixir para a cura da deficiência, da homossexualidade e da cor... pois é na diversidade que está a beleza das relações humanas e no tempo. Tempo sim! Pois com ele aprendemos a respeitar e conviver com as diferenças e a respeitá-las.

Marcus Galvão (2019)

De acordo com a Organização Mundial da Saúde (OMS) no mundo existem mais de 1 bilhão de pessoas que vivem com alguma deficiência, representando $10 \%$ da população mundial. O presidente da ONU, António Guterres, salienta que em muitas sociedades as pessoas com deficiência acabam frequentemente desconectadas, vivendo isoladas e enfrentando discriminação. Destaca ainda que há um crescente número de boas práticas que criam uma sociedade mais inclusiva onde estas pessoas podem viver de forma independente. (OMS, 2020)

O Brasil, a partir da Convenção sobre os Direitos das Pessoas com Deficiência, criou o Estatuto da Pessoa com Deficiência (Lei no 13.146, de 6 de julho de 2015) que discorre sobre a concepção/abordagem da deficiência, caminhando de um modelo médico, no qual a deficiência é entendida como uma limitação do indivíduo, para um modelo social e mais abrangente, que compreende a deficiência como resultado das limitações e estruturas do corpo, mas também da influência de fatores sociais e ambientais do meio no qual a pessoa está inserida (BRASIL, 2015).

A educação deveria ser um direito fundamental para o exercício da cidadania, porém dadas as condições objetivas da sociedade capitalista, deve-se questionar o não atendimento a esse direito, em especial ao lidar com a educação especial em sua dimensão inclusiva e de possibilitar aos educandos o desenvolvimento de suas potencialidades, buscando atender às necessidades de cada um dentro dos aportes teóricos e práticos da atividade docente.
* Mestre em Ciências da Saúde. Secretaria Municipal de Saúde de Goiânia e de Aparecida de Goiânia.

E-mail: markusvag@gmail.com

\footnotetext{
** Mestre em Ensino na Educação Básica. Secretaria Municipal de Educação (SME) de Aparecida de Goiânia e Secretaria Estadual de Educação de Goiás (Seduc).

E-mail: giselebaianinha@hotmail.com

*** Doutora em Educação. Secretaria Municipal de Educação de Goiânia (SME) e Secretaria Estadual de Educação de Goiás (Seduc).

E-mail: welmalegnaterra@gmail.com
} 
Ao refletir sobre a educação da pessoa com deficiência, esse direito não deveria se diferenciar, contudo na sociedade que privilegia a regulamentação da normalidade, o trabalho na educação especial torna-se um desafio que requer alteridade e resistência às imposições ideológicas que advém de instâncias que desconhecem tal realidade na prática efetiva.

Neste trabalho, apresentam-se os limites e as potencialidades dos educandos do Centro de Educação Especial (CAE) Peter Pan, baseando-se na execução de um musical, no qual pode-se observar e confirmar o desenvolvimento físico, mental, intelectual, moral, emocional, espiritual e social, em condições de liberdade e igualdade, considerando ainda que é um processo que requer tempo e dedicação.

Em consonância com os aspectos mencionados, a arte em suas diversas linguagens como a música, o teatro e a dança, vem a corroborar com o desenvolvimento dos educandos, proporcionando uma interação em que a suas potencialidades são suscitadas com base em uma ação educativa. Nesse caso específico, da apresentação de um musical com a participação de todos os educandos especiais, na concepção da diversidade cultural.

Nessa perspectiva, o diferente, o imprevisível e a limitação compõem a beleza do musical, que teve como tema "As aventuras no CAE Peter Pan" ${ }^{1}$, nome escolhido a partir da peça teatral escrita por J. M. Barrie na qual um pequeno rapaz se recusa a crescer e passa a vida a ter aventuras mágicas. Porém, diferente da vida aventureira e mágica desse personagem, nossos educandos vivenciam "aventuras" e conquistas cotidianamente, mas contra as dificuldades impostas pela deficiência e seguem em constante busca da superação de suas limitações e serem aceitos na sociedade de forma espontânea e não estabelecida por lei. Este estudo vem mostrar como as artes em suas diversas linguagens possibilitam o contato com o seu corpo, sua existência e a do outro, o respeito e a aceitação ao diferente a fim de valorizar os diversos tipos de inteligência dos educandos.

\section{Breve histórico: educação especial e o Centro de Atendimento Especializado (CAE) Peter Pan}

A Assembleia Geral das Nações Unidas, em 1948, proclamou a Declaração Universal dos Direitos Humanos, na qual reconhece que a educação é direito fundamental para o exercício da cidadania:

Todos os seres humanos nascem livres e iguais, em dignidade e direitos [...] sem distinção alguma, nomeadamente de raça, de cor, de sexo, de língua, de religião, de opinião política ou outra, de origem nacional ou 
social. Todos são iguais perante a lei e, sem distinção, têm direito a igual proteção da lei à educação (1948, p. 1).

A partir da década de 1950, começaram a surgir às primeiras escolas especializadas e as classes especiais. Brasil (2006) salienta que a Educação Especial se estabilizou como um subsistema da Educação Comum, período este no qual predominou a concepção científica da deficiência, acompanhada pela atitude social do assistencialismo reproduzida pelas instituições filantrópicas em atendimentos segregadores e patologistas.

Diante das especificidades desses elementos de contexto de inclusão, cabe pensar na importância das artes na formação integral dos sujeitos que precisam de uma atenção especial às suas necessidades "a estratégia de jogar com a simplicidade dos comportamentos casuais, mais autênticos, sem cerimônias, frente a um preparo técnico-corporal preciso, será tendência significativa dos movimentos de vanguarda da dança pós- anos 1970" (GERALDI, 2012, p. 22). Com os movimentos de vanguarda lançam-se ideias de resistências ao cenário político e cultural em que a sociedade estava vivendo e que precisava ser contestado e modificado em sua base estrutural, inclusive na educação.

Deste modo, em 1980 os resultados da integração escolar começam a ser criticadas e reivindicadas, sob alegação de que as crianças com maior comprometimento eram mantidas separadas das demais, em classes especiais e centros de atendimento separados da escola regular. Essas concepções estenderam-se em muitos países como Itália, Inglaterra, Estados Unidos, França, Suécia, Espanha e outros. Nesse mesmo ano, devido à pressão internacional, objetivos da escola inclusiva passaram a visar à "unificação dos sistemas de ensino especial com o sistema de ensino geral, a inclusão de alunos com deficiências no ensino comum, oferecendo as mesmas oportunidades e recursos a todos os alunos" (RUBIO, 1998, p.116), representando um avanço educacional e social numa mudança de paradigma, garantindo oportunidades iguais e uma escola para todos.

De acordo com Gimenez et al. (2011), no Brasil, o atendimento especializado às pessoas com necessidades especiais teve início na época do Império. Destacam-se duas instituições que foram criadas em 1854 - Imperial Instituto dos Meninos Cegos, atual Instituto Benjamin Constant (IBC) no Rio de Janeiro e em 1857 - Instituto dos Surdos Mudos, atual Instituto Nacional da Educação dos Surdos (INES) também no Rio de Janeiro. Diante deste contexto histórico de inclusão foi criado o Instituto Pestalozzi em Porto Alegre no ano de 1926 com ações efetivas até a atualidade. 
Na metade do século XIX, a deficiência intelectual era vista pela família e pela sociedade como uma forma de loucura e tinha que ser tratada em hospícios ou manicômios, atualmente Centro de Atendimento Psicossocial. Apesar da ancestralidade desses "problemas" que atingia muitas famílias, com filhos considerados idiotas, estudos sobre a institucionalização da deficiência intelectual são bastante recentes, datando no início do século XX (FOUCAULT, 1978; ENGEL, 1995; 2001; JUNIOR, 1987; LACAZ, 1966).

Embora a Constituição Federal de 1988, em seu artigo 208, estabeleça a integração escolar enquanto preceito constitucional, preconizando o atendimento aos indivíduos que apresentam deficiência, algumas instituições de ensino reagem de forma excludente com a discussão de não ter recursos materiais e humanos suficientes e aptos a oferecer o serviço ao educando.

De acordo com Lanna Júnior (2011) o modelo de atendimento às pessoas com deficiência, representa um avanço no processo social, pois se baseava em uma perspectiva exclusivamente clinicopatológica da deficiência, apesar de muitos que ainda vêem a deficiência de forma excludente, gerando desigualdade entre as pessoas. $\mathrm{O}$ modelo médico ignora o papel das estruturas sociais na opressão e exclusão das pessoas com deficiência e desconhece as articulações entre deficiência e fatores sociais, políticos e econômicos.

A União das Associações Pestalozzianas dá início a luta contra as estruturas sociais opressoras e excludentes por meio do Movimento Pestaloziano desde 1926 oferecendo gratuitamente diversos serviços (saúde, social e educação) voltados para as pessoas com deficiência em no Brasil. O movimento conta com 221 integrantes entre associações, federações estaduais e entidades análogas. Atende cerca de 32 mil de pessoas com deficiência em 19 estados e no Distrito Federal. Os Institutos Pestalozzianos são inspirados no ideário do pedagogo suíço Johann Heinrich Pestalozzi (1746-1827). A influência do ideário de Pestalozzi, no entanto, ganhou impulso definitivo com Helena Antipoff, educadora e psicóloga russa que, a convite do Governo do Estado de Minas Gerais, veio trabalhar na recém-criada Escola de Aperfeiçoamento de Belo Horizonte.

A criação da Federação Nacional das Sociedades Pestalozzi (Fenasp), também por iniciativa de Helena Antipoff, fomentou o surgimento de várias sociedades Pestalozzi pelo Brasil. Atualmente, existem cerca de 150 delas filiadas à Fenasp, além de outras instituições que lutam em prol ao atendimento das pessoas com algum tipo de deficiência.

O Centro de Atendimento Especializado CAE Peter Pan (PP) foi a primeira unidade aberta em Goiânia e deu 
origem à Associação Pestalozzi de Goiânia. Atualmente, o atendimento do CAE PP é voltado para pessoas com deficiência intelectual, autismo ou síndromes a partir de 6 anos. Conta com 3 unidades, todas com foco no atendimento da pessoa com deficiência Intelectual, Transtorno do Espectro Autista e Síndromes. Para este público são desenvolvidos: o Ensino Fundamental - Programa Pedagógico Especializado (PEE) e Ensino Especializado em Transtornos do Espectro Autista (PEE TEA). Outro serviço é o Atendimento Educacional Especializado (PAEE) destinado a crianças a partir de 5 anos que estejam estudando na rede regular de ensino e precisam de complementação no contra turno e viabilizar um conjunto de atividades para facilitar o processo ensino-aprendizagem, proporcionando condições ao desenvolvimento global dos educando nas áreas: pedagógica, extraclasse (visitas sócio educativas), atividades de vida diária (AVD), cozinha educativa, serviço social, atendimentos psicológicos, musicoterápico, psicomotricidade, educação aquática e informática educativa.

As ações desenvolvidas pela instituição são desenvolvidas com o intuito de promover uma melhorar a qualidade de vida, autonomia, assim como a capacidade de definir e promover o desenvolvimento. Pontos este discutidos na Conferência Mundial sobre Educação para Todos, em Jomtien (1990), Tailândia, que defende a "educação é um direito fundamental de todos, mulheres e homens, de todas as idades, no mundo inteiro" o documento ainda destaca que a "educação pode contribuir para conquistar um mundo mais seguro, mais sadio, mais próspero e ambientalmente mais puro, que, ao mesmo tempo, favoreça o progresso social, econômico e cultural, a tolerância e a cooperação internacional". (UNESCO, 1990).

Em termos gerais, a educação que hoje é ministrada apresenta graves deficiências, faz-se necessário torná-la mais relevante para melhorar sua qualidade, além disso, estar universalmente disponível para promover o respeito à dignidade humana.

Nesse caso, na educação inclusiva, a apresentação de um musical com a participação de educandos, como o realizado pelo CAE PP pode ser considerado como espaço privilegiado da diversidade cultural. Entendida aqui como uma microcultura em que o fenômeno psicológico é resultado dos fatores culturais da macrocultura (RATNER, 2011), e, portanto, ambas as culturas - pessoal e coletiva são produtoras de identidade.

Este relato oportuniza o conhecimento da comunidade científica a fatores importantes no que se diz respeito da pessoa com deficiência com as diversas linguagens artísticas, pois a partir da arte compreende-se as formas e possibilidades do educando com alguma deficiência por meio do 
musical, além de possibilitar mudanças no comportamento dos educandos demonstrando a si próprio e à comunidade que são capazes de produzir uma dinâmica de encantamento por meio da arte e da expressão corporal com dança e a música/musicoterapia apropriadas ao contexto. Por isto o presente estudo tem o objetivo de discutir o musical como ferramenta para a potencialização das diversas habilidades de educandos com deficiência.

\section{Metodologia}

Trata-se de um estudo qualitativo do tipo descritivo desenvolvido para a construção do espetáculo realizado no ano de 2014. Os dados foram coletados a partir de diário de bordo do profissional responsável pela idealização, criação e direção - Musicoterapeuta - com especialização em Desenvolvimento Humano, Educação e Inclusão. O período de escrita, planejamento, ensaios foi de seis meses.

A metodologia criada para a realização de um espetáculo de pessoas com deficiência foi pensada no sentido de compreender a relevância da educação e da arte com sujeitos que às vezes ficam à margem da sociedade por terem habilidades diferentes das exigidas pelo mercado de trabalho, trabalho intensificado pelas tecnologias da informação e da indústria da cultura que buscam adaptar esses sujeitos aos meios de produção e de consumo. Diante de uma realidade social excludente ao diferente em muitas situações, cabe refletir sobre as condições reais em que esses sujeitos se encontram e mostrar as potencialidades dos educandos, como forma de resistência ao preconceito que atinge a sociedade em diversas ocasiões e locais, mesmo revestido por uma ideologia da aceitação ao diferente e ao novo.

Os dados foram analisados a partir dos objetivos traçados por Galvão et. al (2020) descritos neste trabalho e correlacionados com as linguagens artísticas música e dança, possibilitando uma compreensão das possibilidades do fazer artístico da pessoa com deficiência além da inclusão social destas pessoas. Assim, o espetáculo foi descrito em forma de relato de experiência, sendo ensaiado nas dependências de uma Escola Especial do Município de Goiânia.

As diversas linguagens artísticas foram incluídas neste trabalho, como a arte musical e a dança em estilo contemporâneo. Deste modo, torna-se possível discutir o musical como ferramenta para a potencialização das diversas habilidades do educando com deficiência.

\section{Musical no CAE PP: luz, câmera e ação}

O musical, também chamado de "comédia musical”, é a forma teatral mais difundida no mundo de língua 
inglesa do século XX. Desenvolveu-se a partir da Ópera Cômica e do teatro burlesco em Londres no final do século XIX, e alcançou sua forma mais duradoura nas obras de compositores norte-americanos na década de 1930. De acordo com o dicionário Sadie (1994) a maioria dos musicais apresentam um enredo construído sem rigidez, em que se combinam elementos cômicos e românticos; a música consiste geralmente de canções com melodia de fácil apreensão e de caráter sentimental com números de conjunto e danças.

A dança é a expressão representativa de diversos aspectos da vida do homem, acompanha-o ininterruptamente através de sua história em todos os momentos de sua existência, servindo como elemento de comunicação e afirmação, e dando-lhe possibilidade de viver plenamente através de seu próprio corpo (HOLANDA CAMILO, 2017, p. 57).

A dança pode ser considerada como uma "linguagem social” (SOARES, 1992, p. 83), já que, nos momentos importantes da vida humana, "nascimento, procriação, morte, para manifestar sua luta pela vida, seu amor, sua alegria e seu desamparo, o homem dança, só ou junto aos seus semelhantes" (BRITÂNICA, 1982, p. 3152). Essa dança incorpora uma cultura de pertencimento à origem, de reconhecimento de seus valores e costumes, podendo inclusive se apresentar como uma busca pela interação entre os membros de seu grupo social.

Observa-se que, "antes de ser uma forma de arte, a dança foi uma expressão espontânea da vida coletiva à qual dava uma vigorosa e expressiva acentuação" (LE BOULCH, 1987, p. 76-77, apud HOLANDA CAMILO, 2017). Essa forma de arte é expressa na linguagem afetiva dos educandos quando se envolvem de maneira lúdica e sensível com o objeto de prazer da arte, estabelecendo uma relação de aprendizagem e de desenvolvimento em diversas áreas de sua vida.

A arte como forma de expressão do humano, advém de tempos remotos da humanidade, o que se apresentava como comédia e tragédia desde os gregos com seus feitos em um processo civilizatório que foi se reeditando e atribuindo novos valores. No contexto deste estudo, o musical como forma de terapia "dramaterapia", surgiu entre a década de 1940 e 1950 nos Estados Unidos utilizando fantoches nas sessões terapêuticas. Anos depois, em 1979, no mesmo país surge a Associação Nacional de Drama Terapia.

Brandalise (2015) cita uma série de populações que eram tratadas com esta forma de terapia: pacientes psiquiátricos, pessoas com atraso no desenvolvimento, crianças 
em idade pré-escolar, adolescentes com diferentes necessidades, idosos, pessoas com Síndrome de Down, pessoas com bulimia, usuários de drogas, moradores de rua, pessoas com stress pós-traumático após agressão, vítimas de abusos sexuais e pacientes com fibromialgia.

O musical no CAE Peter Pan foi produzido pela primeira vez na instituição no ano de 2012 no turno vespertino como uma proposta do Projeto Arte e Movimento para abertura da Mostra Pedagógica do corrente ano, com a finalidade de mostrar aos pais e à sociedade o trabalho desenvolvido pelos profissionais. Este musical foi criado, a princípio, com o objetivo específico de cumprir aos ditames burocrático de expor o trabalho realizado pelos profissionais de musicoterapia e do educador físico.

Sua primeira edição teve como tema o conto de João Barro: A formiguinha e a neve. Como proposta de atividade pedagógica, contou com o envolvimento e engajamento de todos os profissionais da escola e dos educandos. Por parte dos profissionais, o trabalho cotidiano foi de explicar sobre a apresentação, reforçando a ideia com os alunos e a produção dos figurinos. A alegria em participar, em poder mostrar suas fantasias construídas, aumentou a frequência dos educandos na escola e nos ensaios. O resultado do esforço deste trabalho, com envolvimento dos profissionais e dos educandos veio por meio de um belo espetáculo, grandes sorrisos, algumas lágrimas de emoção e uma salva de palmas em um anfiteatro lotado. Em sua segunda edição, o tema foi “Arca de Noé - Vinicius de Moraes", não diferente da edição anterior, o envolvimento e o engajamento à proposta contribuíram para o êxito da apresentação.

A partir destas duas edições supracitadas, a direção e coordenadores da instituição decidiram incorporar o musical como um evento fixo no calendário de atividades da instituição, passando assim a ser realizado anualmente. Galvão et. al (2020) elenca os principais objetivos do teatro musical realizado com pessoas com deficiência, são eles:

- Possibilitar liberdade de expressão e criatividade aos educandos.

- Proporcionar o desenvolvimento dos interesses, potencialidades e capacidades.

- Ser performativo (mostrando desenvolvimento através da ação).

- Promover relações intrapessoais e interpessoais

No sentido terapêutico, o musical serve como um espaço para expressão criativa e terapêutica:

- Promover um sentimento de realização e satisfação de uma forma orientada a recursos ("Eu sou capaz de fazê-lo”). 
- Fornecer aos pais e parentes, ao público, o envolvimento pessoal com seu filho/ filha / parente de uma "distância teatral segura” (ou seja, o elemento ecológico).

- Promover a inclusão social através do ativismo e da participação.

- Proporcionar a integração entre os alunos, profissionais, pais, parentes e o público em geral.

O nome dado ao espetáculo faz referência ao nome da escola e a obra literária, como pode ser observado no flyer de divulgação do evento, conforme a Figura 1 abaixo.

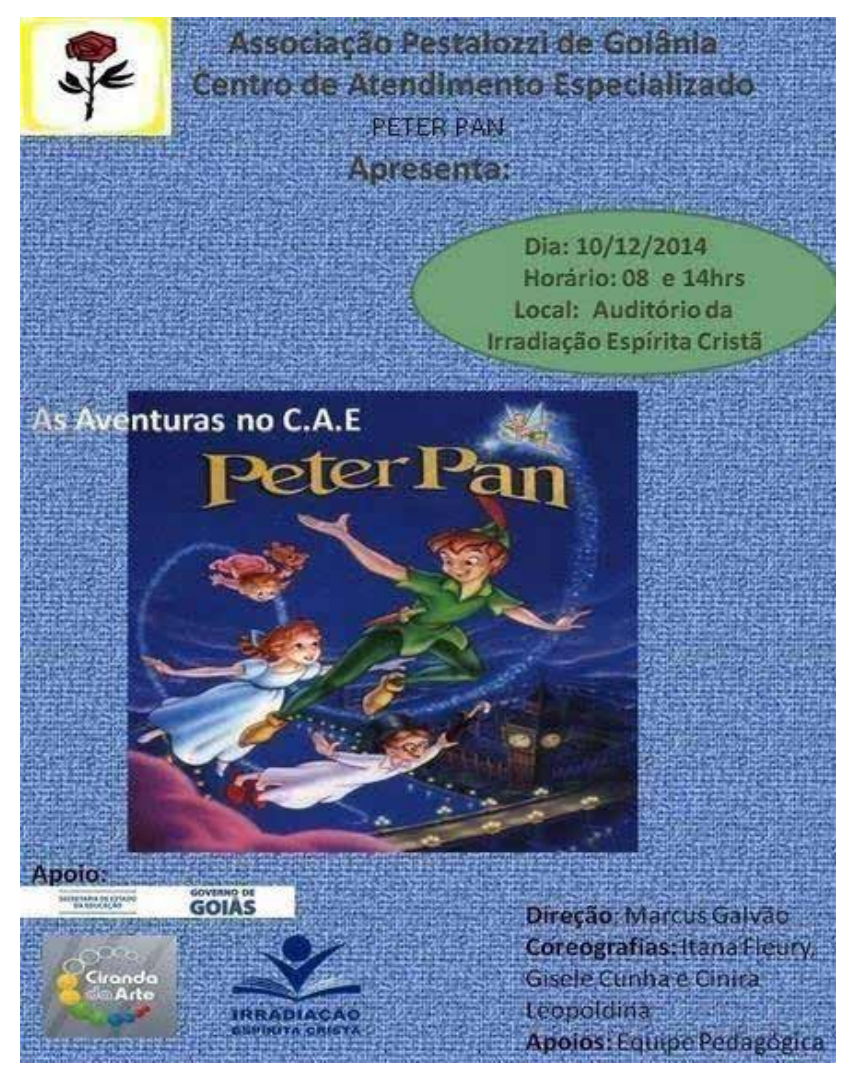

Figura 1 - Flyer de divulgação do evento. Fonte: registro dos autores (2020).

O espetáculo descrito teve como tema o nome da escola "As aventuras no CAE PETER PAN". As etapas do processo de criação foram estruturadas e construídas tendo como base as necessidades observadas nas edições anteriores e foram divididas em oito etapas e duas fases, como pode ser observado:

Primeira etapa: Escolha do tema/história

Esta etapa foi realizada pelo musicoterapeuta/diretor do musical. Após estudar a história do Peter Pan, seleciona as principais partes tendo como foco a exposição de todos os personagens da história (Wendy e irmãos, Sininho, Capitão Gancho). 
Segunda etapa: Estruturação de enredo.

Este foi pensado para ser flexível, com o objetivo de acolher as necessidades especializadas, aproveitar o interesse e a criatividade, estimulando as potencialidades de cada educando. Esse apresentava na estrutura o entrelaçamento entre a fala do narrador, as encenações e as danças.

Terceira etapa: músicas, figurinos, cenário e coreografias.

A escolha das músicas, baseadas no contexto/momento da história e as personagens, por exemplo: no momento que a Sininho joga o pó mágico para Wendy e seus irmãos voarem com o Peter Pan para a Terra do Nunca, tinha a finalidade de apresentar o conteúdo do musical de forma lúdica e compreensível aos espectadores.

Os figurinos, em sua maioria, foram adaptados do "acervo" disponível pela Ciranda da Arte - subsecretaria de educação e cultura do Governo do Estado de Goiás e parte do construídos pelos profissionais (pedagogas, terapeuta ocupacional e mães dos educandos) com TNT e/ou doações.

O cenário foi constituído por três painéis pintados em uma base de papelão, sendo um com a imagem do céu, um de um navio de pirata e uma janela (Figura 2).

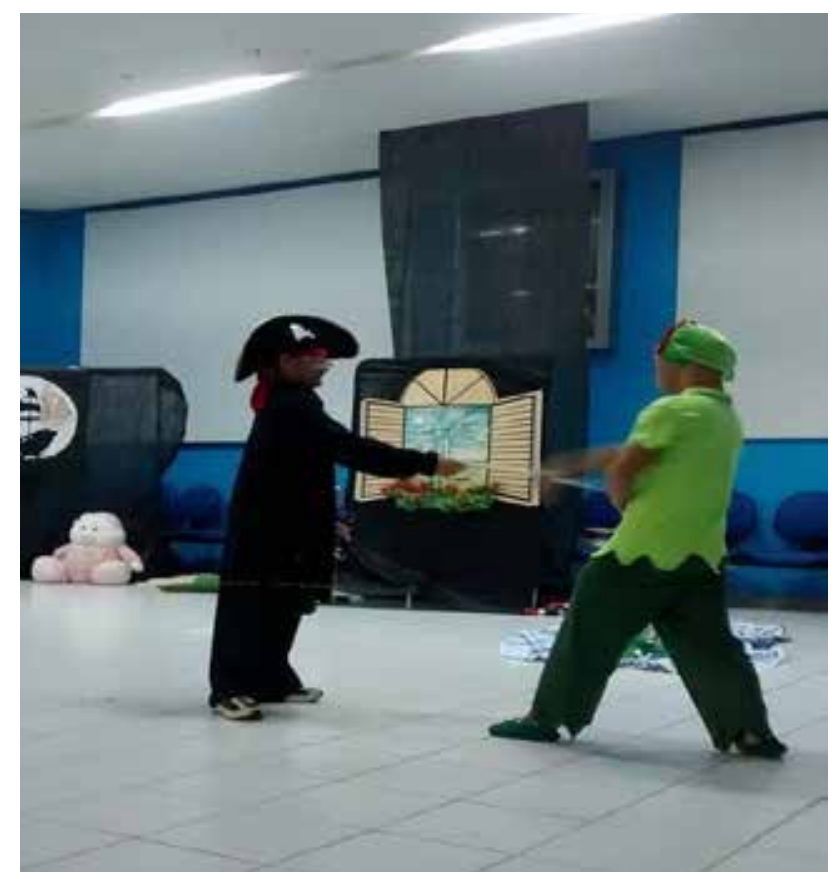

Figura 2 - Painéis pintados. Fonte: Os autores (2020).

As coreografias, limitadas em seis, foram criadas pensando nas potencialidades e limitações dos educandos, conforme o agrupamento das salas de aula, na tentativa de possibilitar a participação de todos. Para o levantamento destas coreografias foram inseridas diversas músicas com a observação da expressão corporal dos educandos. Somen- 
te a partir deste momento foram organizados os conteúdos expostos pelos educandos. Assim, os educandos cadeirantes e os com baixa mobilidade integraram o mesmo grupo. Com este grupo foi explorado os membros superiores utilizando o uso de fitas coloridas na execução da dança (Figura 3).

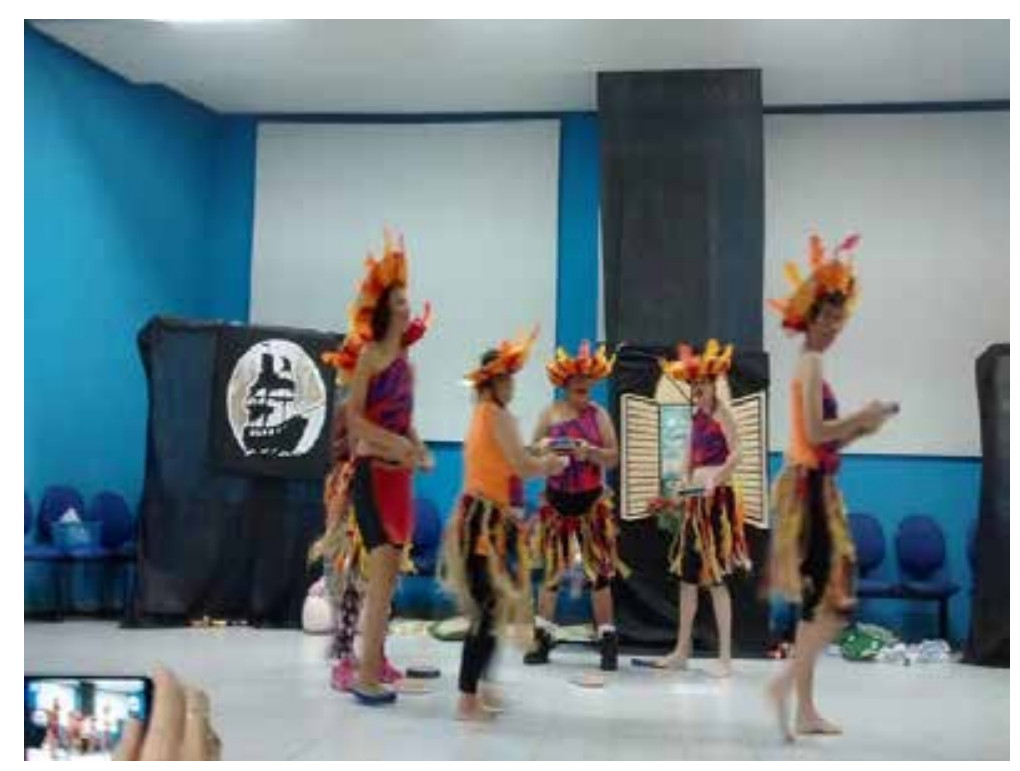

Figura 3 - Integração dos educandos cadeirantes e com baixa mobilidade.

Fonte: Os autores (2020).

Quarta etapa: Preparação psicológica dos educandos.

Esta parte consistia na utilização de recursos audiovisuais e atividades artísticas (parte direcionada as profissionais pedagogas, psicólogas e fonoaudióloga).

Quinta etapa: Ensaios.

Os ensaios aconteciam duas vezes por semana, divididos por personagens. Os ensaios gerais aconteciam nas duas semanas que antecediam a apresentação, sendo um na escola e um no local de realização do espetáculo, onde os educandos já utilizavam as fantasias.

No dia da apresentação as seguintes etapas foram seguidas:

Sexta etapa: Acolhimento dos alunos, maquiagem e fantasiá-los

Etapa realizada pelas pedagogas e psicologia, com intuito de explicar/revisar para os educandos o que acontecerá e o papel deles.

Oitava etapa: Condução ao local da apresentação;

Nona etapa: Direcionamento e auxílio durante a apresentação; 
Salienta-se que em todas as etapas o profissional musicoterapeuta e educador físico estiveram envolvidos. O leitor pode perguntar: onde a musicoterapia se encaixa ao se tratar de um musical? O que caracteriza isso como musicoterapia? De acordo com Brandalize (2015) a musicoterapia está em todos os estágios. Quando os educandos começam a expressar suas vontades e/ou seus conteúdos, o musicoterapeuta e/ou psicólogo são apoiados por nós verbalmente e/ou musicalmente, a partir da escuta terapêutica ativa ao longo dos oito estágios.

A instituição estabeleceu parcerias que proporcionaram maior auditório, fantasias e, além desses recursos físicos e materiais disponibilizados para o musical, houve o empenho e entusiasmo dos educandos e de suas famílias para um evento de grande porte.

A equipe envolvida estava disposta a trabalhar com afinco, na constante busca pelo equilíbrio, o respeito às limitações, a valorização das potencialidades e a intervenção dos educadores na preparação do musical, como forma de possibilitar o desenvolvimento de suas habilidades, com autonomia e liberdade de pensamento e ação, na construção de um projeto escolar em que acolheu a todos independente de suas condições específicas, pois foi considerado a sua totalidade de sentido pedagógico.

O musical foi apresentado no dia 10 de dezembro, com duas apresentações e participação de 120 educandos, nos dois períodos. O espetáculo teve duração aproximadamente de 40 minutos e foi subdividido por blocos de personagens que iam surgindo no decorrer do enredo: Peter Pans, Capitão Gancho e Sininho.

\section{Discussão}

O musical propiciou aos educandos mais que um momento recreativo, o reconhecimento de suas potencialidades e o desenvolvimento de suas habilidades motoras, cognitivas e emocionais, que em grupo e com incentivo de suas capacidades e compreensão de suas limitações, podem alcançar projetos que encantam a sociedade. Conforme Corrêa (2003, p. 28) há uma série de benefícios dessa prática, pois é a partir do "[...] brincar, no jogar, que a criança internaliza toda a sua ação de ser e de conviver. É brincando que ela reconhece o outro e o seu espaço, é brincando que ela aprende as regras sociais, pois necessita esperar a sua vez". As brincadeiras podem refletir na ação das crianças aquilo que elas percebem no seu contexto como uma forma de imitação da realidade e o uso da fantasia para a produção de sua realidade infantil.

A música, o teatro e a dança também podem ser utilizados com o propósito supracitado, mas sabe-se das 
implicações e das potencialidades que cada linguagem proporciona aos educandos com deficiência. Nessa perspectiva Tarragô, Habowski e Conte (2017) salientam que

O trabalho pedagógico com o uso da arte dança, teatro e música - auxilia na ampliação de relações entre crianças com limitação cognitiva e/ou social com o mundo externo, melhora a qualidade em suas interações sociais, enriquece a autoestima, através do reconhecimento de suas potencialidades, desenvolve a aprendizagem e rompe barreiras cognitivas, afetivas e sociais.

Segundo Cunha (2017), a dança como forma de inclusão é uma arte que inclui pessoas com deficiência e pode contribuir para o desenvolvimento de suas habilidades básicas e socialização. A autora mostra a importância de movimentar parte do conhecimento do mundo e de seus limites, tendo relação com a necessidade de conquista de desejos, liberdade, alegrias, confiança e segurança. Assim, a dança pode favorecer à pessoa com deficiência, o desenvolvimento desta habilidade, mostrando à sociedade suas capacidades de realizar algo aparentemente impossível, constituindo uma forma de minimizar o ser diferente, o que auxilia na troca de diálogos mais interativos e significativos entre o mundo externo e o interno.

De acordo com Louro (2006) ao discorrer sobre a música e sua utilização salienta que este é um instrumento importante para o aprimoramento da comunicação. Deste modo, com muita frequência assume aspectos de recreação, sendo certamente fonte comprovada de reabilitação, dando base para afirmação sobre as diversas dimensões que são acessadas a partir da atividade musical.

Segundo, Maciel et al (2009), a dança e demais atividades de expressão corporal como o teatro e a música, proporcionam um melhor desenvolvimento físico e organofuncional (aparelhos cardiorrespiratórios, excretor e circulatório). Além disso, estimula a independência, a interação e a experiência sensorial-motora com outras pessoas, em relacionamentos solidificados na segurança e na afetividade, que possibilitem o desenvolvimento da autonomia, da criatividade e da alteridade será capaz de beneficiar a formação do sujeito em sua totalidade de sentidos. Nos aspectos psicossociais, aumenta a autoestima, a autovalorização e aceitação de si com seus limites e potencialidades, dentre outros benefícios que são inerentes ao processo de participação nessas atividades desportivas e artísticas.

Galvão (2019) discorre que a partir da compreensão do musical como mediador da socialização da história e da cultura na inclusão, é possível observar as potencialidades 
e a importância da utilização das artes - dança, teatro e a música - como linguagens condensadas em um espetáculo artístico. O autor se embasa no livro de Vygostky "A formação social da mente" que introduz a questão da cultura ao discutir sobre os problemas do desenvolvimento da criança e a aquisição das formas conscientes de conduta denominados processos psicológicos superiores, como a atenção voluntária, o pensamento, a linguagem, a memória e lógicas na resolução de tarefas.

Carvalho (2011, p. 28) ao referir que "pensar inclusão a partir da perspectiva da educação na diversidade é reconhecer as diferenças individuais; é reconhecer a existência de limitações que criam barreiras que precisam ser removidas, sem considerá-las como obstáculos intransponíveis".

Deste modo, a linguagem do gesto e das posições da música e da dança, é incapaz de analisar um personagem, de revelar os pensamentos de uma pessoa ou mesmo de elucidar estados de consciência com clareza e precisão da linguagem verbal. Na compreensão de questões sobre essa realidade, vale indagar: afinal, quem disse que o teatro foi criado para analisar personagens, para resolver conflitos do amor e do dever, para lutar com todos os problemas da natureza tópica atual e psicológica que monopolizam os palcos contemporâneos?

Segundo Michèle Febvre (1995), a dança Ocidental é percorrida por meio do duo/dueto entre a virtuosidade e a expressividade, entre a dança pura e a dança teatral. Dois pólos, ou duas tentações, em torno das quais, desde o século XVII, a dança articulou, acentuando uma ou outra dimensão dependendo da época e dos criadores.

Cintra (2002) evidencia os benefícios da dança, e salienta a importância para além dos ditos normais. O desenvolvimento depende da capacidade que cada um tem de se movimentar no mundo e estar experimentando novas sensações a cada dia, ou seja, se para o deficiente este aspecto se vê pouco desenvolvido, a dança vem para propiciar futuras aquisições de movimentos e uma adequada consciência corporal que o ajuda a conquistar tal objetivo, além de trabalhar a inclusão do aluno com deficiência na sociedade.

Vivenciar a dança e a música para pessoas com deficiência é uma experiência significativa, é perceber as coisas mais simples do dia-a-dia, é algo que faz o corpo desabrochar, movimentos se aflorarem, ressaltando os sentidos do corpo e seus limites, incorporando o que foi aprendido não apenas para realizar aulas, mais levando tudo para seu próprio mundo e sua vida.

Figueiredo (1997) em suas pesquisas mostra que as atividades artísticas, entre elas a dança e a música, trazem vida, movimento e bem-estar para a pessoa com deficiência, dando possibilidades para uma vida com mais 
liberdade, alegria e principalmente resistência na luta por um mundo sem preconceitos e com mais interação entre as pessoas, deficientes ou não, em condições de sociabilidade e inclusão.

Segundo Cunha (2017), as pessoas com deficiência intelectual, por apresentarem atraso no aspecto sensorial, linguagem e experiência sociocultural, sua inserção em atividades de dança, música, pintura, propiciam uma melhora significativa nesses aspectos, trazendo benefícios para esse tipo de deficiência.

A prática pedagógica com adaptações que atendessem aos interesses e necessidades desses educandos traria benefício sem sua aprendizagem para a vida de maneira lúdica e espontânea? Como descreve Cintra (2002), a prática dessa área deve ser trabalhada totalmente dotada de prazer e espontaneidade, fazendo com que os deficientes enfrentem seus medos, frustrações, anseios, dificuldades e que o corpo consiga executar movimentos, expressando sentimentos, ao demonstrar realmente a existência corporal e humana.

Seria muito mais simples, ocorrer a integração da criança deficiente na escola para os ditos "normais", se colocássemos de lado o preconceito, e olhássemos mais para o potencial, que é o fruto da investigação individual do professor, e deixássemos de lado as limitações, que estas são visíveis, e facilmente detectadas (CINTRA, 2002, p. 16).

Ao buscar na literatura, conteúdos sobre a integração das linguagens para o deficiente, a dramaterapia e musicoterapia surgem, como dito anteriormente, com a intencionalidade pedagógica e com o aparato das áreas do conhecimento sobre a educação especial e do trabalho de todos os profissionais que empenham em possibilitar o desenvolvimento integral dos educandos. Contudo, não é foco deste artigo discutir sobre a utilização destas terapêuticas no evento relatado, mas não se pode apenas ignorar estes trabalhos de grande relevância social e acadêmica.

A literatura apresenta algumas formas de trabalho utilizando a combinação da música, musicoterapia, dança e o teatro. Cohen (1985) propõe o uso do canto e do ritmo como proposta para o uso da musical. Salas (1990), musicoterapeuta, aponta que os trabalhos envolvendo a musicoterapia e o teatro são raros, em seu trabalho com crianças deficientes ele utiliza o playback, no espetáculo é construído com base nas histórias pessoais dos atores que as contam.

A música vem para contribuir, juntamente com a dança, para proporcionar maior comunicação entre os 
educandos, estimulando a autoaceitação e ajudando na busca da autonomia perdida pelas limitações da deficiência.

$\mathrm{O}$ ato de desenvolver uma linguagem híbrida na qual o teatro se relaciona com a dança e a poesia, entre outras mídias, remete ao olhar de inacabamento. Em seus estudos aponta que o hibridismo não significa uma adição de diferentes conceitos de mídia, nem a ação de estabelecer entre as mídias obras isoladas, mas uma integração de conceitos estéticos das diferentes mídias o em um novo contexto. Ainda a respeito desta questão de hibridismo, a bailarina e pesquisadora de dança, Sílvia Geraldi (2012) afirma que:

A cena da dança dos últimos decênios expõe um panorama de produção complexo e multiforme, marcado pelo hibridismo, heterogeneidade, fragmentação e transversalidade de formas e discursos. Esse caráter plural torna-se visível também nos modos de ação de seus criadores e na oferta extremamente generosa de técnicas e metodologias de trabalho de que dispõem para confecção de sua arte. (GERALDI, 2012, p. 13).

A dança e a música neste contexto marcado pelo hidridismo traz aos pesquisadores o desafio de pensar em novas alternativas de arte diante das contradições existentes na sociedade. Neste musical a adaptação de elementos artísticos teve a intencionalidade de provocar a surpreendente condição de potencialidade que os educandos têm, mas que é ignorado como incapazes de produzir algo admirável e belo, discussão esta que ainda é incipiente dentro do espaço escolar.

A escola como organismo social, motivando a colaboração entre pais, grupos de estudos e comissões de trabalho, promove um estreito contato com a escola e os professores, facilitando os processos de sociabilização na escola, e proporcionando um ambiente para a inclusão a partir de uma pedagogia mais humana.

De modo geral, a finalização da pesquisa tornou evidente que é preciso, além da formação continuada, uma mudança nas atitudes para a questão de inclusão. $O$ fato de haver políticas públicas para a educação na perspectiva inclusiva não assegura o ensino inclusivo, mas depende fundamentalmente de professores comprometidos com os ideais da educação.

\section{Considerações finais}

Na produção deste relato, destaca-se o termo evento híbrido. O objetivo deste trabalho não foi o de refletir somente sobre esse conceito especificamente, mas também 
de relatar como as diversas linguagens artísticas no palco transpõem barreiras e expandem a atuação do Musicoterapeuta, do Pedagogo e do Educador Físico para além da sala de aula, quadra ou o setting com elementos musicais, verbais e corporais e como estes contribuem na formação dos educandos em diversas dimensões da humanização destes sujeitos, partícipes de um processo que possibilite o desenvolvimento da autonomia e a valorização de suas potencialidades cognitivas e da expressão estética corporal pela arte, em seu contexto cultural de inclusão.

\section{Referências}

BRANDALISE, André. Music therapy and theatre: a community music therapy socio-cultural proposal for the inclusion of persons with autism spectrum disorders. Voices: A World Forum for Music Therapy, [S.l.], v. 15, n. 1, feb. 2015 .

BRITÂNICA. Enciclopédia Mirador Internacional. São Paulo: Britânica Publicações Ltda., v. 3 e 7, 1982.

CARVALHO, Silvia Pereira. Os primeiros anos são para sempre. Mestre em psicologia da educação pela PUC-SP, coordenadora executiva do Instituto Avisa Lá Formação Continuada de Educadores, 2011. Disponível em: www.avisala.org.br. Acesso em: 10 out. 2017.

CINTRA, Rosana Carla Gonçalves Gomes. Educação especial $\mathbf{x}$ dança: um diálogo possível. Campo Grande: UCDB, 2002.

CORRÊA, Bárbara R. do P. Gimenez. O brincar: fundamentos, implicações pedagógicas, decorrências sociais. Revista Educação em Movimento, v. 2, n. 5. p. 25-32. maio/ago. 2003.

CUNHA, Gisele Bizerra da. Dança e deficiência intelectual: um estudo com educandos da rede municipal de ensino de Aparecida de Goiânia. 2017. 96f .Dissertação (Mestrado em Educação Básica) - Programa de Pós-Graduação em Ensino na Educação Básica do Centro de Ensino e Pesquisa Aplicada à Educação da Universidade Federal de Goiás, Goiás, 2017.

BRASIL. MINISTÉRIO PÚBLICO DE GOIÁS. Declaração Universal dos Direitos Humanos. Disponível em: http://www.mp.go.gov.br/portalweb/hp/7/docs/declaracao_universal_dos_direitos_do_homem.pdf. Acesso em: 07/11/2020. 
SADIE, S. Dicionário Grove de música: edição concisa. (Org). Tradução, Eduardo Francisco Alves, Rio de Janeiro: Jorge Zahar Ed.,1994.

ENGEL, Magali Gouveia. A loucura na cidade do Rio de Janeiro: idéias e vivências, 1830-1930. Resgate: Revista Interdisciplinar de Cultura, v. 6, n. 1, p. 133-136, 2006.

FEBVRE, Michèle. Danse contemporaine et théâtralité. Paris: Editions Chiron, 1995.

FIGUEIREDO, Valéria M. C. Olhar para o Corpo que Dança: um sentido para a pessoa portadora de deficiência visual. 1997. Tese (Mestrado em Educação Física) - Universidade Estadual de Campinas, Campinas, 1997.

FOUCAULT, Michel. História da loucura na Idade Clássica. São Paulo: Ed. Perspectiva, 1978.

GALVÃO, M. V. A. et al. O musical como meio de valorização das potencialidades de educandos com deficiência por meio da música e dança. In: CAMILO, C. H. (Org). Tópicos da Educação Física, 2020.

GALVÃO, M. V. A. O musical como elemento transformador em práticas inclusivas entre jovens adultos com deficiências múltiplas. 2019. $63 \mathrm{f}$. Trabalho Final de Curso (Especialização) - Universidade de Brasília, Instituto de Psicologia (FE). Programa de Pós-Graduação em Processo de Desenvolvimento Humano e Saúde, Brasília, 2019.

GARDNER, Howard. Inteligências múltiplas: a teoria na prática. Porto Alegre: Artes Médicas, 1995.

GERALDI, Sílvia. O lugar da teatralidade na dança contemporânea. Revista Sala Preta PPGAC, v. 12, n. 2, dez., 2012. p. 13-26.

GIMENEZ, Marli; GONÇALVES, Pedro; AMORIM, Scheila. Musicoterapia e a Educação Inclusiva. Revista Brasileira de Musicoterapia. Ano XIII, n. 11, 2011.

HOLANDA CAMILO, Christiane. Cultura e arte na dança para deficientes. Goiânia: Expressão Acadêmica, 2017.

JUNIOR, Benilton Bezerra et al. Cidadania e Loucura: Políticas de Saúde Mental no Brasil. Petrópolis: Editora Vozes, 1987.

LACAZ, Carlos da Silva. Vultos da Medicina Brasileira. São Paulo: Helicon, 1966. 
LANNA JÚNIOR, Mário Cléber Martins. As primeiras ações e organizações voltadas para as pessoas com deficiência. Disponível em: http://www.bengalalegal. com/asprimeiras-historia-pcd. Acesso em: 10 out. 2017.

LE BOULCH, Jean. Rumo a uma ciência do movimento humano. Trad. Jeni Wolff. Porto Alegre: Artes Médicas, 1987.

LOURO, Viviane dos Santos. Educação musical e deficiência: propostas pedagógicas. São José dos Campos, São Paulo: Editora do Autor, 2006.

MACIEL, Lilian de Fátima; CAMARGO, César Alex; JUNIOR, Guanis de Barros Vilela. Reflexões sobre a dança em cadeira de rodas, seus benefícios e contribuições na vida dos deficientes físicos. Disponível em: http://www.guanis.org/cpaqv/v1n2_lilian_maciel. pdf. Acesso em: 10 out 2017.

RATNER, Carl. Macro cultural psychology: a political philosophy of mind. Oxford University Press: New York, 2012.

RUBIO, C. G. Educación Especial: de la integración escolar a la escuela inclusiva. Valencia: Promolivro, 1998.

SOARES, Carmen Lúcia et al. Metodologia do ensino da Educação Física. São Paulo: Cortez, 1992.

TARRAGÔ, Lenon da Silva; HABOWSKI,Adilson Cristiano; CONTE, Elaine. A inclusão social por meio das artes: possibilidades e limites na educação. Revista Gestão Universitária. Disponível em: http://www.gestaouniversitaria.com.br/artigos/a-inclusao-social-por-meio-das-artes-possibilidades-e-limites-na-educacao. Acesso em: 18 nov. 2020.

Enviado em: 11-05-2020

Aceito em: 19-11-2020

Publicado em: 14-12-2020 